\title{
Recherche
}

\section{Clostridium difficile-associated diarrhea in a region of Quebec from 1991 to 2003: a changing pattern of disease severity}

\author{
Jacques Pépin, Louis Valiquette, Marie-Eve Alary, Philippe Villemure, Anick Pelletier, \\ Karine Forget, Karine Pépin, Daniel Chouinard
}

Fast-tracked article. Published at www.cmaj.ca on Aug. 4, 2004.

Abstract

Background: Recent reports suggest that Clostridium difficile colitis may be evolving into a more severe disease. During the second half of 2002 we noted an increase in the number of patients with severe $C$. difficile-associated diarrhea (CDAD) in our institution. We describe cases of CDAD at our institution over a 13year period and investigate changes in illness severity.

Methods: We undertook a retrospective chart review of all cases of CDAD diagnosed at the Centre hospitalier universitaire de Sherbrooke from Jan. 1, 1991, to Dec. 31, 2003. Because the hospital serves a well-defined population of Quebec, we were also able to calculate population-based incidence during this period. We abstracted data on individual patients from patient charts and from hospital and pharmacy computer databases. We defined cases of CDAD as having a positive C. difficile cytotoxicity assay result, or endoscopic or histopathological evidence of pseudomembranous colitis. A case was considered complicated if one or more of the following was observed: megacolon, perforation, colectomy, shock requiring vasopressor therapy, or death within 30 days after diagnosis.

Results: A total of 1721 cases of CDAD were diagnosed during the study period. The incidence increased from 35.6 per 100000 population in 1991 to 156.3 per 100000 in 2003; among patients aged 65 years or more, it increased from 102.0 to 866.5 per 100000 . The proportion of cases that were complicated increased from $7.1 \%(12 / 169)$ in 1991-1992 to $18.2 \%(71 / 390)$ in $2003(p<0.001)$, and the proportion of patients who died within 30 days after diagnosis increased from $4.7 \%(8 / 169)$ in $1991-1992$ to $13.8 \%(54 / 390)$ in 2003 ( $p<$ $0.001)$. A high leukocyte count $\left(20.0 \times 10^{\circ} / \mathrm{L}\right.$ or greater $)$ and an elevated creatinine level (200 $\mu \mathrm{mol} / \mathrm{L}$ or greater) were strongly associated with adverse outcomes: in 2003, 45 (40.9\%) of 110 patients with a high leukocyte count or creatinine level, or both, had complicated CDAD and 28 (25.5\%) died within 30 days after diagnosis. After adjustment for age and other confounding factors, patients initially given oral vancomycin therapy had a risk of progression to complicated CDAD that was $79 \%$ lower than the risk among patients initially treated with metronidazole (adjusted odds ratio 0.2, 95\% confidence interval $0.06-0.8, p=0.02$ ).
Interpretation: An epidemic of CDAD with an increased casefatality rate has had important consequences on the elderly population of our region. Our observational data suggest that the equivalence of vancomycin and metronidazole in the treatment of CDAD needs to be questioned.

CMAJ 2004;171(5):466-72

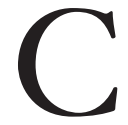
lostridium difficile is an important cause of diarrhea in industrialized countries and the leading cause of infectious diarrhea among patients in hospital. ${ }^{1-6}$ In the second half of 2002 we noted an increase in the number of patients with fulminant $C$. difficile colitis in our institution who required an emergency colectomy. Informal discussions with clinicians from other hospitals in southern Quebec suggested that this phenomenon was occurring in other cities as well. To investigate whether this was related merely to an increase in the number of cases of $C$. difficileassociated diarrhea (CDAD) or to an increase in the proportion of cases that developed severe colitis, we undertook a retrospective study of all cases of CDAD diagnosed at our institution over a 13-year period and investigated changes in illness severity.

\section{Methods}

We undertook a retrospective chart review of all cases of CDAD diagnosed at the Centre hospitalier universitaire de Sherbrooke (CHUS) from Jan. 1, 1991, to Dec. 31, 2003. This 683bed hospital provides secondary and tertiary care to the inhabitants of the Estrie region (Eastern Townships) of the province of Quebec. Because the hospital serves a well-defined population of Quebec, we were also able to calculate population-based incidence during this period. The Estrie population increased over the study period, from 274670 in 1991 to 294058 in 2003, according to annual estimates made by the regional health authority from the most recent census data. About half of the population lives in Sherbrooke (134 981 in 1991 and 146559 in 2003). The CHUS clinical microbiology laboratory is the sole regional laboratory performing $C$. difficile toxin assays for all but 2 primary 
care facilities, which send their specimens to laboratories outside the region. The CHUS laboratory receives nearly all requests for $C$. difficile toxin assays for residents of Sherbrooke, and about $60 \%$ of those for residents in the Estrie region who live outside of Sherbrooke.

The same $C$. difficile toxin B cytotoxin assay was used throughout the study period, using either Vero cells or MRC-5 cells, with readings after 24 and 48 hours of incubation and neutralization with C. difficile antitoxin (Bartels Inc., Issaquah, Wash.). Until mid-1996, the cytotoxin assay was routinely performed on all stool samples received for culture; afterward, it had to be specifically requested. Since the end of 1990, patient records at the CHUS, including those of patients at other institutions whose stool specimens were analyzed at the CHUS laboratory, have been entered into a computer database, with the exception of medical and nursing notes. We chose Jan. 1, 1991, as the start of the observation period because we could from then on identify nearly all cases (both inpatients and outpatients) with a positive cytotoxin assay result through the hospital computerized medical records. In addition, we searched the hospital discharge database for all patients who died or left the hospital with a recorded diagnosis of pseudomembranous colitis, antibiotic-associated colitis or $C$. difficile colitis.

We defined cases of CDAD as those meeting at least one of the following criteria: a positive cytotoxin assay result; endoscopic evidence of pseudomembranous colitis; and histopathological evidence of pseudomembranous colitis on a specimen obtained during endoscopy, colectomy or autopsy. We excluded patients with a discharge diagnosis of pseudomembranous colitis, $C$. difficile colitis or antibiotic-associated colitis but without any supporting evidence. Two episodes of CDAD occurring in the same patient were considered distinct events if they occurred more than 3 months apart; an episode occurring within 3 months of a prior one was considered a relapse. We defined CDAD as hospitalacquired if the patient was in hospital when the inciting antibiotics were administered. A case of CDAD was considered to be complicated if the patient died within 30 days after the diagnosis of CDAD or if any of the following occurred: megacolon, perforation, colectomy or shock requiring vasopressor therapy.

We reviewed patient records from the CHUS database. For patients whose stool specimens were sent to the CHUS without being seen by one of its staff physicians, only the information that accompanied the specimen (patient name, address, sex, date of birth) was available; this was used to calculate incidence rates, but such patients did not contribute to measures of disease severity. For patients seen at the CHUS (both inpatients and outpatients), we abstracted clinical and laboratory data, including the use of antibiotics, tube feeding or surgery during the 2 months before the diagnosis of CDAD, evidence of immunosuppression (defined as the presence of leukemia, lymphoma, HIV infection, neutropenia, organ transplantation or use of immunosuppressive drugs), antibiotics used for the treatment of CDAD and evidence of complications. Peak leukocyte count and creatinine level corresponded to the highest value within 1 week after diagnosis of CDAD.

We also tracked the use of antibiotics among all CHUS inpatients, regardless of whether they had CDAD, by reviewing data from a pharmacy database for 1999-2003. For each antibiotic, we estimated the number of patient-days of use by dividing the total number of grams dispensed during the year by the defined daily dosage (the latter determined by consensus of local infectious diseases consultants).

For statistical analysis, proportions were compared with the Yates-corrected $\chi^{2}$ test or Fisher's exact test when numbers were small. Unconditional logistic regression was used for multivariate analyses. Models were built up sequentially, starting with the variable most strongly associated with the outcome and continuing until no other variable reached significance or altered the odds ratios of variables already in the model. When the final model was reached, each variable was dropped in turn to assess its effect. Different models were compared using the likelihood ratio test.

\section{Results}

A total of 1721 new cases of CDAD were identified during the 13-year study period, $1658(96.3 \%)$ of which had a positive cytotoxin assay result. Of those without a positive cytotoxin assay result, 59 had endoscopic changes typical of pseudomembranous colitis, and 4 were diagnosed on histopathological grounds. Fig. 1 shows the incidence of CDAD among residents of Sherbrooke during the study period. The annual incidence increased from 35.6 per 100000 population in 1991 to 156.3 per 100000 in 2003. Among residents in the Estrie region outside of Sherbrooke, the incidence remained stable from 1991 to 2002 (22.2 and 25.2 per 100000 respectively) and increased in 2003 (92.2 per 100 000); however, incidence rates are probably underestimated, since referral of cases and specimens was incomplete and may have changed over time. Agespecific incidence rates in Sherbrooke are also shown in Fig. 1. The incidence among children decreased after 1996, when the cytotoxin assay had to be specifically requested. Among people aged 18-64 years, the incidence increased only in 2003 . Among people aged 65 years or more, the annual incidence increased 10-fold during the study period, up to 866.5 cases per 100000 in 2003; the incidence was 1681 per 100000 among those aged 80 years or more.

The case-fatality rate and the proportion of cases that were considered complicated more than doubled over time, as measured among the 1675 new cases for whom enough information was available to assess these outcomes (Table 1). The absolute number of patients who had megacolon, perforation or shock requiring vasopressor therapy, who needed a colectomy or who died within 30 days after diagnosis of CDAD increased dramatically, from 6-10 such cases per year during 1991-1998 to 71 cases in 2003. After adjustment for age, sex, initial treatment of CDAD, immune status, and tube feeding and surgery in the 2 months preceding diagnosis, cases diagnosed in 2003 had a higher likelihood of having complicated CDAD than those diagnosed in previous years. In these models, the peak leukocyte counts and creatinine levels were not included because these parameters are clearly on the causal pathway between year of diagnosis and the outcomes.

From 1991 to 2002 the proportion of cases in which complicated CDAD developed and the proportion of cases in which death occurred within 30 days after diagnosis were $25.4 \%$ (68/268) and $19.0 \%$ (51/268) respectively among patients with a high leukocyte count $\left(20.0 \times 10^{\circ} / \mathrm{L}\right.$ or greater), an elevated creatinine level $(200 \mu \mathrm{mol} / \mathrm{L}$ or greater $)$ or both. 
The corresponding proportions among patients with lower leukocyte counts and creatinine levels were 6.0\% (40/666) and $4.2 \%(28 / 666)$. In 2003, the proportion of cases with complicated CDAD and the proportion of cases in which death occurred within 30 days after diagnosis increased, both among patients with high leukocyte counts, creatinine levels or both (40.9\% [45/110] and 25.5\% [28/110] respectively) and among those with lower leukocyte counts and creatinine levels (12.3\% [25/204] and $11.3 \%$ [23/204] respectively). In 2003, of the 110 patients with high leukocyte counts, creatinine levels, or both, 87 were initially given metronidazole; complicated CDAD developed in 34 (39.1\%) of them, including $20(23.0 \%)$ who died within 30 days after diagnosis. Only 2 such patients were initially given vancomycin, none of whom had complicated CDAD.

Factors associated with complicated CDAD, in uni-

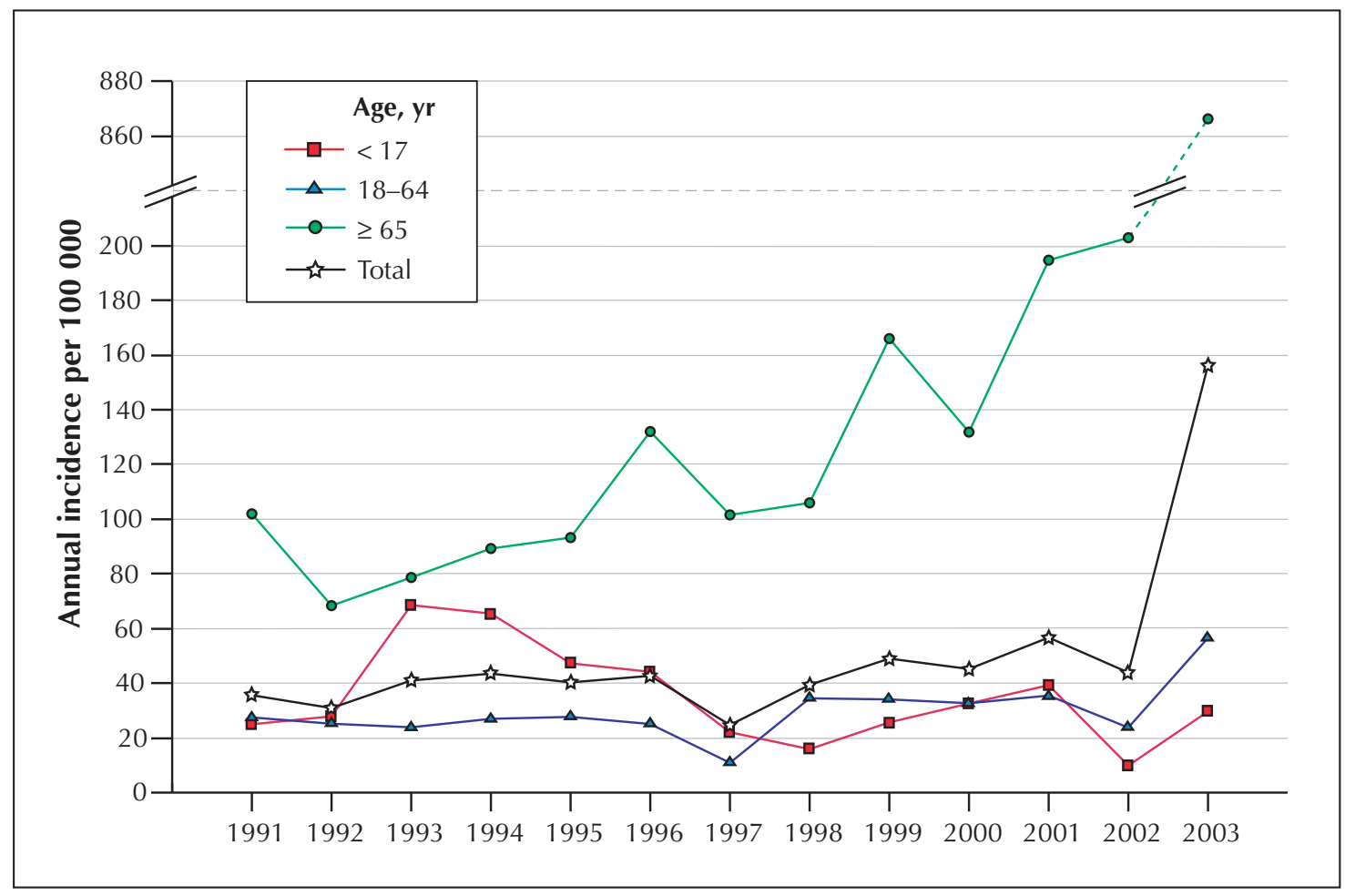

Fig. 1: Annual incidence (per 100000 population) of Clostridium difficile-associated diarrhea (CDAD) in Sherbrooke, Que., 1991-2003.

Table 1: Patients with Clostridium difficile-associated diarrhea (CDAD) in the Estrie region of Quebec who died within 30 days after diagnosis or who had complicated CDAD, 1991-2003

\begin{tabular}{|c|c|c|c|c|c|}
\hline Period & $\begin{array}{l}\text { No. of patients } \\
\text { with CDAD* }\end{array}$ & $\begin{array}{l}\text { No. }(\%) \text { who died } \\
\text { within } 30 \text { days } \\
\text { after diagnosis }\end{array}$ & $\begin{array}{c}\text { Adjusted OR } \\
(95 \% \mathrm{Cl}) \dagger\end{array}$ & $\begin{array}{c}\text { No. }(\%) \text { who } \\
\text { had complicated } \\
\text { CDAD }\end{array}$ & $\begin{array}{c}\text { Adjusted OR } \\
(95 \% \mathrm{Cl}) \dagger\end{array}$ \\
\hline 1991-1992 & 169 & $8 \quad(4.7)$ & 1.0 & 12 (7.1) & 1.0 \\
\hline 1993-1994 & 217 & $11 \quad(5.1)$ & $1.7(0.5-5.3)$ & 14 & $1.0(0.4-2.7)$ \\
\hline 1995-1996 & 215 & $13 \quad(6.0)$ & $1.6(0.5-5.0)$ & $17 \quad(7.9)$ & $0.9(0.3-2.2)$ \\
\hline 1997-1998 & 192 & $11 \quad(5.7)$ & $1.1(0.4-3.7)$ & $13 \quad(6.8)$ & $0.6(0.3-1.7)$ \\
\hline 1999-2000 & 248 & 19 (7.7) & $1.5(0.5-4.6)$ & $28(11.3)$ & $1.2(0.5-2.9)$ \\
\hline 2001-2002 & 244 & 21 (8.6) & $1.6(0.5-4.7)$ & $28(11.5)$ & $1.1(0.5-2.5)$ \\
\hline 2003 & 390 & $54(13.8)$ & $3.0(1.1-8.4)$ & $71(18.2)$ & $2.2(1.0-4.9)$ \\
\hline$p$ value & & $<0.001 \S$ & $<0.0019$ & $<0.001 \S$ & 0.001 ब \\
\hline
\end{tabular}

Note: $\mathrm{OR}=$ odds ratio, $\mathrm{Cl}$ = confidence interval.

*Includes only patients for whom enough information was available to assess these outcomes.

†Adjusted for age, sex, initial treatment, immune status, and tube feeding and surgery in the 2 months preceding diagnosis; 1991-1992 was used as the baseline period.

łPresence of one or more of the following: megacolon, perforation, colectomy, shock requiring vasopressor therapy, death within 30 days after diagnosis.

$\$ \chi^{2}$ test for trend.

$\uparrow \chi^{2}$ test, comparing 2003 with all other years. 
variate and multivariate analyses, are shown in Table 2 . The population for these analyses included inpatients of the CHUS and the outpatients for whom enough information was available to assess whether they had complicated CDAD. Sex and fever were no longer significant in the multivariate analysis. The independent factors associated with complicated CDAD were age of 65 years or more, hospital-acquired CDAD, tube feeding in the 2 months preceding diagnosis, not having had surgery in the 2 months preceding diagnosis, immunosuppression, a peak leukocyte count of $20.0 \times 10^{9} / \mathrm{L}$ or greater and renal failure. After adjusting for these confounding factors, initial treatment with vancomycin was associated with a $79 \%$ lower risk of complicated CDAD compared with initial treatment with metronidazole (adjusted odds ratio 0.2, 95\% confidence interval $0.06-0.8, p=$ $0.02)$. In contrast, initial treatment with metronidazole was not associated with a more favourable outcome compared with no treatment. In these models, which attempted to document short-term correlates of adverse outcomes, peak leukocyte count and creatinine level were included, and year of diagnosis was no longer found to enhance significantly the fit of the models, because part of the enhanced severity of CDAD in recent years was captured by leukocyte count and creatinine level.

Fig. 2 shows the variations over time in the distribution of antibiotics that seemed to provoke CDAD among 1364 patients (515 with community-acquired CDAD and 849 with hospital-acquired infection) for whom information was available on the use of antibiotics in the 2 months preceding diagnosis. Overall, more than two-thirds of the CDAD cases had received cephalosporins in the 2 months before diagnosis. The proportion of patients who had received quinolones increased progressively, up to $55 \%$ in 2003 , whereas the proportion who had received aminoglycosides decreased. This might to some extent reflect changes in patterns of use of antimicrobial agents and in the distribution of hospitalversus community-acquired cases. Thus, in Table 3 we show the rate of hospital-acquired CDAD per 1000 patient-days of antibiotic use among all CHUS inpatients. For the calculation of this rate, the numerator corresponds to the number of CHUS patients (regardless of city of residence) with hospital-acquired CDAD who received a given class of antibiotic in the 2 months before diagnosis, and the denominator corresponds to the number of patient-days that this class of antibiotic was used among all CHUS inpatients during these years. Compared with the rates in 1999-2002, the rate in 2003 was higher for all classes of antibiotics except cotrimoxazole. Antibiotics associated with the highest risk of CDAD were macrolides, third- and second-generation cephalosporins, clindamycin and quinolones.

\begin{tabular}{|c|c|c|c|}
\hline Characteristic & $\begin{array}{c}\% \text { (no.) of patients } \\
\text { with complicated } \\
\text { CDAD } \dagger\end{array}$ & $\begin{array}{r}\text { Unadjusted } \\
\text { OR }(95 \% \mathrm{Cl})\end{array}$ & $\begin{array}{c}\text { Adjusted } \\
\text { OR }(95 \% \mathrm{Cl}) \neq\end{array}$ \\
\hline \multicolumn{4}{|l|}{ Sex } \\
\hline Female & $8.7 \quad(82 / 940)$ & 1.0 & \multirow[t]{2}{*}{-} \\
\hline Male & $13.7(101 / 735)$ & $1.7(1.2-2.3)$ & \\
\hline \multicolumn{4}{|l|}{ Age, yr } \\
\hline$\leq 17$ & $1.3 \quad(4 / 301)$ & 1.0 & 1.0 \\
\hline 18-64 & $6.0 \quad(38 / 635)$ & $4.7(1.7-13.4) \Phi$ & $1.6(0.5-5.1)$ \\
\hline$\geq 65$ & $19.1(141 / 739)$ & $17.5(6.4-47.8)^{* * *}$ & $3.4(1.1-10.3)$ ฯ \\
\hline \multicolumn{4}{|l|}{ Place CDAD acquired } \\
\hline Community & $2.0 \quad(15 / 765)$ & 1.0 & 1.0 \\
\hline Hospital & $18.7(168 / 900)$ & $11.5(6.7-19.7)^{* *}$ & $4.6(2.4-8.6)^{* *}$ \\
\hline \multicolumn{4}{|l|}{$\begin{array}{l}\text { Surgery in } 2 \text { mo preceding } \\
\text { diagnosis }\end{array}$} \\
\hline No & $10.8(123 / 1141)$ & 1.0 & 1.0 \\
\hline Yes & $13.4(60 / 448)$ & $1.3(0.9-1.8)$ & $0.6(0.4-0.9)$ ฯ \\
\hline \multicolumn{4}{|l|}{$\begin{array}{l}\text { Tube feeding in } 2 \text { mo preceding } \\
\text { diagnosis }\end{array}$} \\
\hline No & $9.5(135 / 1416)$ & 1.0 & 1.0 \\
\hline Yes & $28.5 \quad(43 / 151)$ & $3.8(2.5-5.6)^{* *}$ & $2.4(1.5-3.9)^{* *}$ \\
\hline \multicolumn{4}{|l|}{ Immunosuppression } \\
\hline No & $9.4(128 / 1358)$ & 1.0 & 1.0 \\
\hline Yes & $21.7 \quad(54 / 249)$ & $2.7(1.9-3.8)^{* *}$ & $2.3(1.5-3.6)^{* *}$ \\
\hline \multicolumn{4}{|l|}{ Fever (temperature $>38.0^{\circ} \mathrm{C}$ ) } \\
\hline No & $8.8 \quad(52 / 592)$ & 1.0 & \multirow[t]{2}{*}{-} \\
\hline Yes & $17.1(123 / 718)$ & $2.1(1.5-3.0)^{* *}$ & \\
\hline \multicolumn{4}{|l|}{ Peak leukocyte count, $\times 10^{9} / \mathrm{L}$} \\
\hline$<10.0$ & $5.4(23 / 423)$ & 1.0 & 1.0 \\
\hline 10.0-19.9 & $9.8(62 / 633)$ & $1.9(1.2-3.1) \Upsilon$ & $1.3(0.8-2.3)$ \\
\hline$\geq 20.0$ & $33.4(96 / 287)$ & $8.7(5.4-14.2)^{* *}$ & $4.8(2.8-8.4)^{* *}$ \\
\hline \multicolumn{4}{|l|}{ Peak creatinine level, $\mu \mathrm{mol} / \mathrm{L}$} \\
\hline$<100$ & $6.8(54 / 797)$ & 1.0 & 1.0 \\
\hline 100-199 & $24.1(78 / 324)$ & $4.4(3.0-6.4)^{* *}$ & $2.2(1.4-3.5)^{* *}$ \\
\hline$\geq 200$ & $32.2(46 / 143)$ & $6.5(4.2-10.2)^{* *}$ & $3.1(1.8-5.2)^{* *}$ \\
\hline \multicolumn{4}{|l|}{ Initial antibiotic treatment $\S$} \\
\hline None & $10.4 \quad(41 / 394)$ & 1.0 & 1.0 \\
\hline Metronidazole & $13.1(125 / 951)$ & $1.3(0.9-1.9)$ & $1.0(0.6-1.6)$ \\
\hline Vancomycin & $5.9 \quad(5 / 85)$ & $0.5(0.2-1.4)$ & $0.2(0.05-0.8)$ ฯ \\
\hline Metronidazole and vancomycin & $60.0 \quad(9 / 15)$ & $12.9(4.4-38.1)^{* *}$ & $3.7(0.9-14.1)$ \\
\hline \multicolumn{4}{|c|}{$\begin{array}{l}\text { *Presence of one or more of the following: megacolon, perforation, colectomy, shock requiring vasopressor therapy, death } \\
\text { within } 30 \text { days after diagnosis. } \\
\text { †Numbers vary owing to missing values for some variables. } \\
\text { †The independent correlates of complicated CDAD are shown in this column along with their adjusted odds ratios. Sex and } \\
\text { presence of fever were no longer significant in multivariate analysis and were dropped from this final model. } \\
\text { \$Antibiotics given on day } 1 \text { of CDAD treatment. } \\
\$ p<0.05 \text {. } \\
{ }^{* *} p<0.001 \text {. }\end{array}$} \\
\hline
\end{tabular}




\section{Interpretation}

Few studies have measured the population incidence of CDAD. In Boston it was found to be only 7.7 per 100000 during 1988-1990.7 In New Mexico the incidence during 1993-1997 was 14.8 per 100000 , reaching 38.5 per 100000 among people aged 65-74 years and 98.9 per 100000 among those aged 75 years or more. ${ }^{8}$ In Sweden the incidence of CDAD in 1995 was 58 per 100000 inhabitants, reaching 121 per 100000 among adults aged $60-79$ and 315 per 100000 among those $80-89 .^{9}$ The incidence of 866.5 per 100000 that we documented in 2003 among adults aged 65 years or more is several times higher and represented a major epidemic among elderly people, most of which was hospital-acquired, with important consequences.

Recent reports suggesting that CDAD might be evolving into a more severe disease included small numbers of patients and did not adjust for age or other confounding factors. ${ }^{10,11}$ Our series documented convincingly an increase in the case-fatality rate of CDAD over the study period, even if some patients died of other causes. The cytotoxicity assay has an excellent specificity, but its sensitivity is only about $82 \% .{ }^{12}$ Our case definition might thus have overestimated the proportion of cases that were complicated, because patients with milder $\mathrm{CDAD}$ who had a negative assay result could be less likely to undergo endoscopy. We found no evidence, however, that use of endoscopy changed over time: in $1991,3.1 \%(6 / 194)$ of cases were diagnosed by endoscopy, as compared with $2.5 \%(10 / 396)$ in 2003 . The change in testing policy in 1996, which resulted in fewer cases being diagnosed in children, might have resulted in a slight bias upwards in the measures of disease severity in subsequent years.

Several factors may have contributed to the emergence of this epidemic. First, following health care reforms promoting ambulatory care, the mean age of patients admitted to hospital in Quebec increased considerably during the last decade, as did the proportion with numerous comorbidities. ${ }^{13}$ Whether because of a less effective immune response against $C$. difficile toxins or because of more frequent administration of antibiotics for the treatment of community- or hospital-acquired infections, elderly people are especially susceptible to $C$. difficile infection., ${ }^{3,14,15}$ Second, decades of insufficient capital investment in Quebec hospitals have resulted in conditions of hygiene that facilitate the transmission of pathogens such as $C$. difficile. Third, our epidemiological evidence suggests that a more virulent strain might be involved; it seems plausible that it might be more transmissible as well.

Vancomycin is recommended by some for the initial treatment of severe cases of CDAD, ${ }^{2,4,16,17}$ with little supporting evidence. Other recent reviews recommend either complete avoidance of vancomycin or its use as a secondline agent in patients with metronidazole failure, ${ }^{3,5,6,18-21}$ to

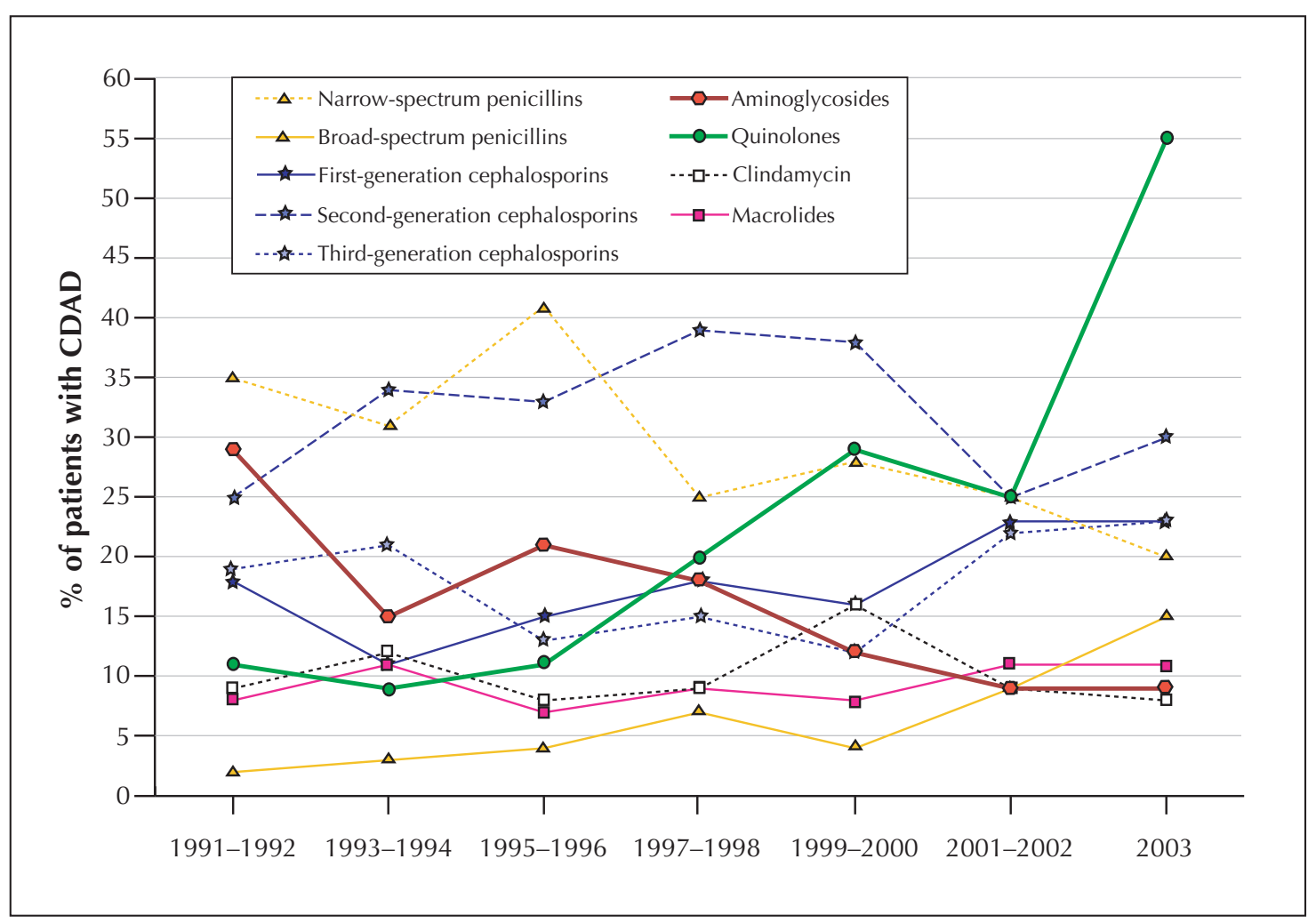

Fig. 2: Proportions of patients with CDAD by class of antibiotic received in the 2 months preceding the diagnosis of CDAD, 1991-2003. 
avoid promoting the emergence of vancomycin-resistant bacteria. Early studies that claimed equivalence of metronidazole and vancomycin were underpowered. ${ }^{22-25}$ A large observational study defined failure as the persistence of diarrhea on day 7, instead of harder end points such as complications of CDAD.$^{26}$ In our institution, the proportion of CDAD patients given vancomycin as the initial treatment decreased from $17 \%$ in the early 1990 s to $3 \%$ in 2003 . After adjustment for confounding factors, CDAD treated initially with metronidazole progressed to complicated $\mathrm{CDAD}$ as frequently as cases left untreated, in contrast to the more favourable outcome with initial vancomycin treatment. This finding should be interpreted cautiously: additional differences in the severity of CDAD upon initiation of treatment (residual confounding) may have been present.

Changes over time in the distribution of antibiotics to some extent reflected variations in the use of these drugs, for instance the replacement of aminoglycosides by quinolones. However, the measures of risk per 1000 patient-days of antibiotic use in our hospital showed that second- and third-generation cephalosporins carried a disproportionate risk of inducing CDAD, as has been observed elsewhere. ${ }^{27-29}$ The high risk associated with macrolides reflected their frequent use with third-generation cephalosporins for the treatment of pneumonia. The risk associated with quinolones increased markedly, whereas that associated with $\beta$ lactam/ $\beta$-lactamase inhibitors was similar to that of narrow-spectrum penicillins. A recent report suggested that gatifloxacin might carry a high risk of CDAD $;^{30}$ this drug is not on our formulary, and instead the quinolones used during the study period were ciprofloxacin and levofloxacin. We found little evidence that changes in prescribing of an- tibiotics influenced the dynamics of CDAD during the study period, as shown in Table 3: the use of quinolones and third-generation cephalosporins increased modestly, whereas the use of second-generation cephalosporins decreased. Paradoxically, the use of $\beta$-lactam $/ \beta$-lactamase inhibitors increased markedly.

Leukocytosis and a high creatinine level were strong and independent factors associated with an increased risk of complicated CDAD. This may have been because they reflect different processes, the former being a marker of severe colon inflammation and the latter, the severity of diarrhea. These simple biological markers could be used to select patients who need more aggressive therapy. Given the observational nature of our study, the association between initial treatment with vancomycin and a more favourable outcome needs to be interpreted prudently. Ideally, a randomized controlled trial should address this issue. At our institution, measures to limit the use of secondand third-generation cephalosporins have been implemented and infection control procedures strengthened, with limited impact so far. Future guidelines for the treatment of common infections should take into consideration the risk of inducing CDAD.

\section{This article has been peer reviewed.}

From the Department of Microbiology and Infectious Diseases, University of Sherbrooke, Sherbrooke, Que.

Competing interests: None declared.

Contributors: Jacques Pépin and Louis Valiquette designed the study and wrote the first draft of the manuscript. All of the authors participated in the data collection and analysis, contributed to subsequent versions of the manuscript and approved the final version to be published.

\begin{tabular}{|c|c|c|c|c|}
\hline \multirow[b]{2}{*}{ Antibiotic class } & \multicolumn{4}{|c|}{ Period; incidence per 1000 patient-days of antibiotic use* } \\
\hline & 1999-2000 & 2001-2002 & & 2003 \\
\hline Narrow-spectrum penicillins & $1.4(28 / 19908)$ & $1.2(25 / 20597)$ & 4.9 & $(53 / 10751)$ \\
\hline$\beta$-lactam $/ \beta$-lactamase inhibitors & $1.0 \quad(7 / 7267)$ & $1.3(17 / 13419)$ & 5.0 & $(46 / 9194)$ \\
\hline \multicolumn{5}{|l|}{ Cephalosporins } \\
\hline First-generation & $2.3(30 / 12779)$ & $2.6(35 / 13633)$ & 8.8 & $(74 / 8412)$ \\
\hline Second-generation & $3.9(55 / 13984)$ & $2.9(36 / 12224)$ & 16.3 & $(92 / 5639)$ \\
\hline Third-generation & $2.7(18 / 6786)$ & $4.6(34 / 7390)$ & 19.5 & $(72 / 3687)$ \\
\hline Carbapenems & $2.7 \quad(7 / 2553)$ & $6.7(15 / 2248)$ & 7.4 & $(9 / 1209)$ \\
\hline Aminoglycosides & $2.4(21 / 8673)$ & $2.2(18 / 8230)$ & 6.5 & $(28 / 4283)$ \\
\hline Quinolones & $1.6(48 / 29693)$ & $1.2(36 / 29375)$ & 9.9 & $(161 / 16293)$ \\
\hline Clindamycin & $4.9(19 / 3861)$ & $3.1(11 / 3508)$ & 11.7 & $(22 / 1880)$ \\
\hline Macrolides & $1.9 \quad(5 / 2625)$ & $4.4(12 / 2715)$ & 20.0 & $(33 / 1649)$ \\
\hline Metronidazole & $2.0(20 / 10092)$ & $1.8(19 / 10696)$ & 5.0 & $(39 / 7745)$ \\
\hline Vancomycin & $2.5 \quad(9 / 3658)$ & $2.4(10 / 4137)$ & 5.2 & $(20 / 3853)$ \\
\hline Cotrimoxazole & $0.2 \quad(8 / 51706)$ & $0.2(13 / 54077)$ & 0.5 & $(11 / 20287)$ \\
\hline
\end{tabular}

*Calculated from numbers in parentheses: the numerator represents the number of patients with hospital-acquired CDAD who received a given class of antibiotic during the 2 months before diagnosis, and the denominator represents the total number of patient-days that this class of antibiotic was used among all inpatients. 


\section{References}

1. Barbut F, Corthier G, Charpak Y, Cerf M, Monteil H, Fosse T, et al. Prevalence and pathogenicity of Clostridium difficile in hospitalized patients. A French multicenter study. Arch Intern Med 1996;156:1449-54.

2. Kelly CP, LaMont JT. Clostridium difficile infection. Annu Rev Med 1998;49: 375-90.

3. McFarland LV. Epidemiology, risk factors and treatments for antibiotic-associated diarrhea. Dig Dis 1998;16:292-307.

4. Fekety R. Guidelines for the diagnosis and management of Clostridium difficile-associated diarrhea and colitis. Am $\mathcal{F}$ Gastroenterol 1997;92:739-50.

5. Johnson SJ, Gerding DN. Clostridium difficile-associated diarrhea. Clin Infect Dis 1998;26:1027-36.

6. Kelly CP, Pothoulakis C, LaMont JT. Clostridium difficile colitis. N Engl 7 Med 1994;330:257-62.

7. Hirschborn LR, Trnka Y, Onderdonk A, Lee MLT, Platt R. Epidemiology of community-acquired Clostridium difficile-associated diarrhea. 7 Infect Dis 1994;169:127-33.

8. Frost F, Hurley JS, Petersen HV, Casciano RN. Estimated incidence of Clostridium difficile infection. Emerg Infect Dis 1999;5:302-3.

9. Karlstrom O, Fryklund B, Tullus K, Burman LG. A prospective nationwide study of Clostridium difficile-associated diarrhea in Sweden. The Swedish $C$ difficile Study Group. Clin Infect Dis 1998;26(1):141-5.

10. Morris AM, Jobe BA, Stoney M, Sheppard BC, Deveney CW, Deveney KE. Clostridium difficile colitis. An increasingly aggressive iatrogenic disease? Arch Surg 2002;137:1096-100.

11. Dallal RM, Harbrecht BG, Boujoukas AJ, Sirio CA, Farkas LM, Lee KK, et al. Fulminant Clostridium difficile: an underappreciated and increasing cause of death and complications. Ann Surg 2002;235:363-72.

12. Staneck JL, Weckbach LS, Allen SD, Siders JA, Gilligan PH, Coppitt G, et al. Multicenter evaluation of four methods for Clostridium difficile detection: ImmunoCard for $C$. difficile, cytotoxin assay, culture and latex agglutination. 7 Clin Microbiol 1996;34:2718-21.

13. Nombre d'hospitalisations, durée de séjour et séjour moyen, en soins de courte durée actifs selon le sexe et la phase de vie, 1992-1993 et 2001-2002. Québec: Ministère de la Santé et des Services Sociaux du Québec. Available: www.msss.gouv.qc.ca/statistiques/produc_util.html (accessed July 2004).

14. Kyne L, Warny M, Qamar A, Kelly CP. Asymptomatic carriage of Clostridium difficile and serum levels of IgG antibody against toxin A. N Engl F Med 2000; 342:390-7.

15. Bignardi GE. Risk factors for Clostridium difficile infection. 7 Hosp Infect 1998;40:1-15.
16. Thielman NM. Antibiotic-associated colitis. In: Mandell GL, Bennett JE, Dolin R, editors. Principles and practice of infectious diseases. 5th ed. Philadephia: Churchill Livingstone; 2000. p. 1111-26.

17. Recommendations for preventing the spread of vancomycin resistance. Recommendations of the Hospital Infection Control Practices Advisory Committee (HICPAC). MMWR Morb Mortal Wkly Rep 1995:44(RR-12):1-13.

18. Bartlett JG. Antibiotic-associated diarrhea. N Engl f Med 2002;346:334-9.

19. Gerding DN, Johnson S, Peterson LR, Mulligan ME, Silva J. Clostridium difficile associated diarrhea and colitis. Infect Control Hosp Epidemiol 1995;16:459-77.

20. Hogenauer C, Hammer HF, Krejs GJ, Reisinger EC. Mechanisms and management of antibiotic-associated diarrhea. Clin Infect Dis 1998;27:702-10.

21. Poutanen SM, Simor AE. Clostridium difficile-associated diarrhea in adults. CMA7 2004;171(1):51-8.

22. Teasley DG, Gerding DN, Olson MM, Peterson LR, Gebhard RL, Schwartz $\mathrm{MJ}$, et al. Prospective randomised trial of metronidazole versus vancomycin for Clostridium difficile-associated diarrhoea and colitis. Lancet 1983;2:1043-6.

23. Wenisch C, Parschalf B, Haselhundl M, Hirschl AM, Graninger W. Comparison of vancomycin, teicoplanin, metronidazole and fusidic acid for the treatment of Clostridium difficile-associated diarrhea. Clin Infect Dis 1996;22:813-8.

24. Bartlett J. Clostridium difficile: clinical considerations. Rev Infect Dis 1990;12 (Suppl 2):S243-51.

25. Wilcox MH, Spencer RC. Clostridium difficile infection: responses, relapses and re-infections. 7 Hosp Infect 1992;22:85-92.

26. Olson MM, Shanholtzer CJ, Lee JT, Gerding DN. Ten years of prospective Clostridium difficile-associated disease surveillance and treatment at the Minneapolis VA Medical Center, 1982-1991. Infect Control Hosp Epidemiol 1994;15:371-81.

27. Khan F, Cheesbrough J. Impact of changes in antibiotic policy on Clostridium difficile-associated diarrhoea (CDAD) over a five year period in a district general hospital. 7 Hosp Infect 2003;54:104-8.

28. Gerding DN. Clindamycin, cephalosporins, fluoroquinolones, and Clostridium difficile-associated diarrhea: This is an antimicrobial resistance problem. Clin Infect Dis 2004;38:646-8.

29. Gorbach SL. Antibiotics and Clostridium difficile. N Engl 7 Med 1999;341: 1690-1.

30. Gaynes R, Rimland D, Killum E, Lowery K, Johnson TM, Killgore G, et al. Outbreak of Clostridium difficile infection in a long term care facility: association with gatifloxacin use. Clin Infect Dis 2004;38:640-5.

Correspondence to: Dr. Jacques Pépin, Centre hospitalier universitaire de Sherbrooke, 3001,12e Avenue Nord, Sherbrooke QC J1H 5N4; fax 819 820-6451; jacques.pepin@usherbrooke.ca

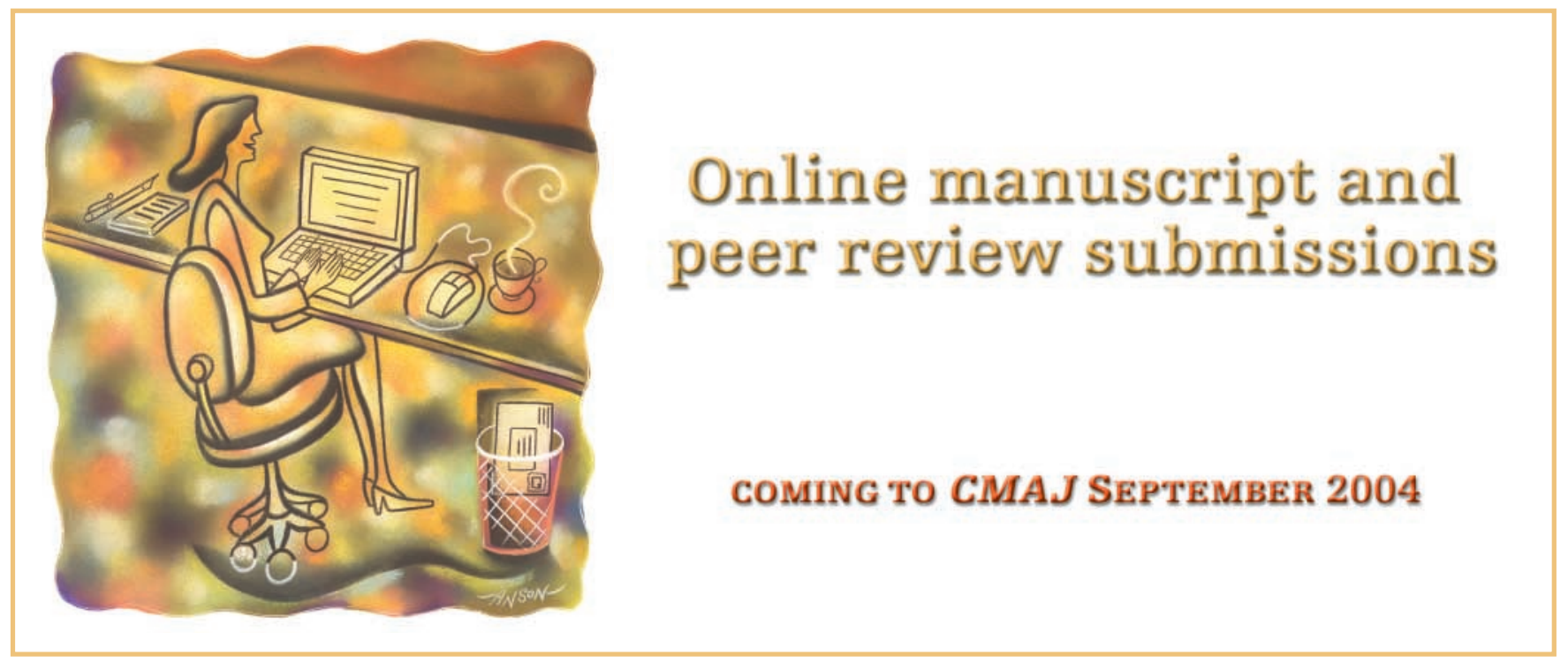

